HUMAN PLACENTAL CYTOPLASMIC 5'-NUUCLEOTIDASE:

115 PURIFICATION AND MOLECULAR PROPERTIES. Vicente Madrid-Marina, Jan Kaminska, and Irving $\mathrm{H}$. Fox University of Michigan, Departments of Internal Medicine and Biological Chemistry, Ann Arbor, Michigan, USA.

Purine nucleotide degradation in human tissues is highly regulated. Dephosphorylation of nucleoside $5^{2}$-monophosphates is the first committed and irreversible reaction of purine nucleotide catabolism. Recent studies indicate that cytoplasmic $5^{\prime}-$ nucleotidase may have an important role in intracellular nucleotide degradation. We purified cytoplasmic $5^{4}$-nucleotidase from human placenta 8075 -fold to a specific activity of $58.85 \mu \mathrm{mi01/}$ $\mathrm{min} / \mathrm{mig}$. The enzyme showed absolute requirement for magnesium with a $\mathrm{Km}$ of $6 \mathrm{mM}$ and $\mathrm{pH}$ optimum from 7.4 to 9.0. CMP and UMP are preferred substrates. A large variety of purine, pyrimidine and pyridine compounds exert an inhibitory effect on enzyme activity. IMP, GMP and NADH produce almost $100 \%$ inhibition at 1.0 mM. Nucleoside di- and triphosphates are potent inhibitors. ATP and ADP are competitive inhibitors with respect to AMP and IMP as substrates with $\mathrm{Ki}$ values of $100 \mu \mathrm{M}$ and $15 \mu \mathrm{M}$; respectively. Inorganic phosphate is a noncompetitive inhibitor with Ki values of $19 \mathrm{mM}$ and $43 \mathrm{mM}$. The estimated molecular weight is 143,000 and the stokes radius is $46.1 \mathrm{~A}$. The subunit molecular weight is 76,000 , suggesting that the enzyme is a dimeric protein. These data elucidate the nature of cytoplasmic $5^{\prime}$-nucleotidase enzyme and its role in purine nucleotide degradation in human tissues.
118 HYPOXANTHINE AND TETRAHYDROBIOPTERTN TREATMENT OF A PATIENT WITH FEATURES OF THE LESCH-NYHAN SYNDROME Hermann Manzke*, Hartmut Gustmann*, Heinz G.Koke* and William L. Nyhan**

*Universitäts-KinderkIinik Kiel, FRG, **University of California - San Diego, Department of

Pediatrics, La Jolla, California, USA

In previous studies on this patient of normal

intelligence $6.9 \%$ of the normal HGPRT activity and an elevated $\mathrm{Km}$ for hypoxanthine in intact fibroblasts had been found. It was thought that perhaps a slight increase in HGPRT activity could alleviate his neurological symptoms. The patient was treated with hypoxanthine $3 \times 1 \mathrm{~g}+$ allopurinol $3 \mathrm{x}$ $100 \mathrm{mg}$ daily for 3 months. Serum hypoxanthine and xanthine rose from 0.4 and 0.35 to $1.53 \pm 0.11$ and $1.19 \pm 0.11 \mathrm{mg} \%$, respectively. His $24 \mathrm{~h}$ urinary excretion of hypoxanthine ranged between 1.34 and $2.02 \mathrm{~g}$. His $24 \mathrm{~h}$ urinary excretion of dopamine was on an average $25 \%$ below our reference values, and his serotonin excretion decreased at $50-70 \%$ of his baseline values. The patient felt quieter and suffered less from disturbances of equilibrium. The therapy had to be interrupted because of renal colics. Treatment with tetrahydrobiopterin had no effect on his neurological symptoms although his urinary dopamine excretion increased significantiy.
116 PURINE ENZYME ACTIVITIES AS MARKERS OF LYMPHOCYTIC DIFFERENTIATION: STUDIES OF LYMPHOCYTES FROH HORSES HORSES WITH SEVERE COMBINED IMUUNODEFICIENCY (SCID). Nancy S. Magnuson, Lance E. Perryman, Carol R. Wyatt and Patricia H. Mason. Washington State University, Department of Microbiology and Pathology, Pullman, Washington, USA. Foals with SCID lack both identifiable B lymphocytes and functional $T$ lymphocytes. Morphological characterization of SCID lymphocytes showed them to be large granular lymphocytes (LGL), a morphology associated with natural killer (NK) cells in human and rat systems. Like NK and T lymphocytes, SCID LGL could be maintained in continuous culture in the presence of interleukin 2 (I1-2). The distribution of cell surface antigens and purine enzymatic activities were evaluated. Surface markers on fresh SCID LGL resembled normal peripheral blood 1ymphocytes (PBL) except for the pan-T marker (26\%, SCID; 627, Normal). Incubation of SCID and normal PBL with IL-2 for 2 weeks increased the percentage of cells carrying the lymphoid precursor (from 10\% to 55\%) and the monocytic (from $3 \%$ to 52\%) markers. Normal PBL, however, lost the pan-T marker (from 627 to 27) while no change was detected for SCID cells. Purine enzymatic activities ( 6 enzymes) for fresh SCID cells were 2 to enzymatic activities ( 6 enzymes) for fresh SCID cells were 2 to
10 times higher than for normal PBL. When normal PBL were maintained in culture with IL-2 for several weeks, morphology and enzymatic activities had changed to those of fresh SCID LGL. These results suggest that LGL from SCID horses may be related to NK or $T$ lymphocytes. (Supported by USPHS grant HD 08886.)

POST-MORTEM OXYPURINE CONCENTRATIONS IN

\section{THE CSF}

Dörner*

Hermann Manzke*, Michael Krämer**, Klaus

Universitäts-Kinderklinik * und Institut für

Rechtsmedizin der Universität**, Kiel, FRG

Post-mortem oxypurine levels in the cerebrospinal

fluid were determined in 77 forensic autopsy cases.

The oxypurine concentrations ranged between 21.8 and $1051.2 \mu \mathrm{mol} / 1$ hypoxanthine, 4.8 and $620.7 \mu \mathrm{mol} / 1$ xanthine, and 6.3 and $1038.1 \mu \mathrm{mol} / 1$ uric acid. The mean values of hypoxanthine $(413 \mu \mathrm{mol} / \mathrm{I}$ and xanthine $(130 \mu \mathrm{mol} / \mathrm{l})$ were about 100 times higher than normal in vivo CSF levels.

Lower values of hypoxanthine were found in cases of sudden death, e.g. traffic accident or myocardial infarction, and higher values in some cases of drug intoxication. There were neither any significant correlations between the hypoxanthine and the xanthine nor between the hypoxanthine or xanthine and the uric acid concentrations. It is assumed that the hypoxanthine level in CSF post mortem reflects the degree of hypoxia preceding death. 119 THE "SWITCH-OFF" MECHANISM OF SPONTANEOUS RESOLU-

Roberto Marcolongo, Angela A.Calabria, Gabrie1la Mazzu1lo, Marina Lalumera, Gabriella Morozzi, Giovanni Cavallo

Institute of Rheumatology-University of Siena, Italy

${ }^{\circ}$ Wellcome-Italia, Res.Lab., Pomezia, Italy

In order to investigate the intriguing problem of the spontaneous resolution of acute gout attack, we examined the hypothesis that occurrence of urate crystals size changes or dissolution by oxygen radicals and/or 1ysosomal enzymes released by stimulated PMNs represents the more 1ikely "switch-off" mechanism. The absorption spectra and the concentrations of uric acid,allantoin and urea were determined before and after in vitro exposition of MSU crystals to $\mathrm{O}_{2}^{-}$flow generated from photoreduction of ribofla vin and $\mathrm{O}_{2}$. The results showed a progressive dissolution of MSU crystals that started after 5 hrs of incubation under $O_{\text {- }}$ flow and was completed after $20 \mathrm{hrs}$.A progressive decrease of uric acid and an increase of allantoin and urea concentration were simultaneously observed.These results were also confirmed by polarizing and electron microscopy and microcalorimetric techniques. Taking into account these observations, the spontaneous resolution of acute gout attack could be attributed to the dissolving effect on urate crystals by oxygen radicals released extracellularly by phagocytising PMNs.

RELATIONSHIPS BETHEEN LIPID AND PURINE METABOLISM:

120 THE BEHAVIOR OF FATTY ACID IN THE PLASMA TRIGLYCERIDES DF GOUTY PATIENTS

Enrico Marine1lo, Lucia Ciccoli $i^{\circ}$, Roberto Leoncini, Roberto Marcolongo ${ }^{\circ}$, Elda Periccioli \& Daniela Vannoni

University of Siena - Departments of Biological Chemistry, 'General Pathology, ${ }^{\circ}$ Rheumatology, "Chemistry - Italy

The composition of fatty acids in plasma triglycerides has been analyzed in 42 gouty patients and 22 controls, by extraction and subsequent yas-chromatography as previously described by $\mathrm{Cic}$ coli et al. (1). The gouty patients present remarkable chances and, specifically, an increase in oleic acid, decreases in arachi donic and linoleic acids, which do not vary according to the are of the subjects and remained the same after a standard diet in which lipids were represented only by olive oil. The picture is similar to that observed both in diabetic and atherosclerotic patients, and we may therefore conclude that gout is another condition in which the ratio of essential fatty acids/monoenoic acid is affected; the relationship of this alteration with purine metabolism is not yet clear and is referred to the hormonal variations observed in gouty patients (2).

(1) Ciccoli L. et al. (1983) Lipids 18, 363-370

(2) Frecolini L. et a). (1983) Clin. Chim. Acta 130, 269-277 